\title{
Avaliação dos componentes do balanço de energia durante o primeiro ano de cultura da banana
}

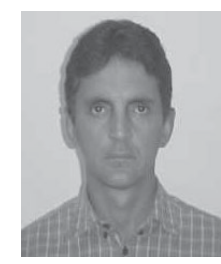

Antônio H. de C. Teixeira ${ }^{1}$

1 Embrapa Semi-Árido, C.P. 23, CEP 56300-970, Petrolina, PE. Fone: (81) 862-1711. E-mail: heribert@cpatsa.embrapa.br

Protocolo $111-04 / 09 / 2000$

\begin{abstract}
Resumo: Dados de saldo de radiação, fluxo de calor no solo, gradientes de temperatura e pressão do vapor, coletados no Campo Experimental da Embrapa Semi-Árido, em Petrolina, PE, foram utilizados na avaliação dos comportamentos diurno e sazonal dos componentes do balanço de energia, durante as fases fenológicas da cultura da banana, irrigada por microaspersão, no primeiro ano de produção. Em média, o saldo de radiação representou $63 \%$ da radiação solar global. A razão de Bowen foi utilizada na medição dos fluxos de calor latente e de calor sensível. A maior porção do saldo de radiação foi usada como fluxo de calor latente (87\%) seguido pelo fluxo de calor no solo (11\%) e pelo fluxo de calor sensível (2\%). 0 baixo percentual do saldo de radiação usado como fluxo de calor sensível deve ser devido à advecção de umidade para a cultura proveniente do Rio São Francisco.
\end{abstract}

Palavras-chave: Musa sp., fluxo de calor latente, fluxo de calor sensível, fluxo de calor no solo, saldo de radiação

\section{Evaluation of components of energy balance in banana crop during the first year}

\begin{abstract}
Data of net radiation, soil heat flux, temperature and vapor pressure gradients, collected at Agrometeorology Experiment Station of Embrapa Semi-árido, at Petrolina, PE, Brazil, were used to evaluate the diurnal and seasonal beheavior of energy balance throughout the phenological phases of the banana crop in the first production cycle, irrigated by microaspersion. On average, the net radiation was $63 \%$ of the global solar radiation. The Bowen ratio was used to measure the latent and sensible fluxes. The higher portion of net radiation was utilized as latent heat flux $(87 \%)$, followed by soil heat flux $(11 \%)$ and by sensible heat flux $(2 \%)$. The lower value of net radiation used as sensible heat flux may be because of the nearness of the São Francisco river that promoted humidity advection to the crop.
\end{abstract}

Key words: Musa sp., latent heat flux, sensible heat flux, soil heat flux, net radiation

\section{INTRODUÇ̃̃O}

Segundo o Levantamento Sistemático da Produção Agrícola, a produção de banana no Nordeste continua sendo a maior do país (em torno de 2,4 milhões de toneladas anuais). O Estado de Pernambuco é o quarto maior produtor nacional, com 0,5 milhão de toneladas (IBGE, 1997). A região do Submédio São Francisco apresenta uma área cultivada com bananeira sob irrigação em torno de 3500 ha, cuja produtividade é competitiva e pode ser aumentada.

O pólo Petrolina, PE/Juazeiro, BA, vem-se destacando na produção de banana cv. Pacovan, usando níveis de média a alta tecnologia. $\mathrm{O}$ aumento crescente do cultivo de bananeira nessa região se deve às condições climáticas, estando situada a baixas latitudes, não há nenhuma restrição ao suprimento de radiação solar para a atividade fotossintética das plantas, a irrigação compensa a heterogeneidade do regime pluviométrico.
Constata-se a existência de poucos estudos sobre os parâmetros agrometeorológicos que atuam na evapotranspiração da cultura da bananeira. Para se fazer irrigação de maneira racional, torna-se necessário o conhecimento dos parâmetros agrometeorológicos que condicionem o consumo hídrico nas diferentes fases fenológicas. Por outro lado, o uso de lisímetros precisos seja a melhor forma de se quantificar a evapotranspiração de uma cultura, a instalação desses instrumentos em fruteiras é sempre difícil e bastante onerosa, razão pela qual se tem recorrido a métodos estimativos, dentre eles se destaca o do balanço de energia.

O processo de evapotranspiração é governado pela troca de energia na superfície vegetada, limitada pela energia disponível, sendo possível estimar-se o fluxo de calor latente de evaporação, através do princípio de conservação da energia, em que o ganho é igual à perda. Com base neste princípio, estima-se a evapotranspiração através da fórmula simplificada da equação 
do balanço de energia, composta pelo saldo de radiação (Rn), pelos fluxos de calor latente (LE) e sensível na atmosfera (H) e pelo fluxo de calor no solo (G). A solução da equação é obtida por medições de Rn e $\mathrm{G}$ e de estimativas de LE e $\mathrm{H}$ através da razão de Bowen ( $\beta$ ) (Teixeira et al., 1999). A falta de instrumentos para medir os componentes individuais do balanço de energia pode ser solucionada com o emprego de expressões empíricas baseadas em parâmetros meteorológicos, as quais, devidamente ajustadas à região e à cultura, conduzem a resultados satisfatórios. O método do balanço de energia tem sido bastante empregado por vários pesquisadores (Garrat, 1984; Gay, 1986; Oliver \& Sene, 1992; Cellier \& Olioso, 1993; Heilman et al., 1994; Prueger et al., 1997; Trambouze et al., 1998), porém, segundo Steduto \& Hsiao (1998) esta técnica deve ser usada com cautela, pois não reflete a natureza turbulenta do processo de evapotranspiração.

De acordo com Angus \& Watts (1984) o método do balanço de energia considera-se a igualdade entre os coeficientes de transferência turbulenta de calor sensível $(\mathrm{Kh})$ e latente $(\mathrm{Kw})$ e esta é válida apenas para condições de estabilidade atmosférica, próximo da neutralidade e as medições dos gradientes de temperatura e umidade devem ser realizadas dentro da camada limite do fluxo de ar, implicando na necessidade de um barlavento com extensão mínima de 100 vezes a altura da cultura. Observaram, ainda, que este método se torna impreciso em condições muito secas ou com considerável advecção de energia.

Por outro lado, Heilman \& Brittin (1989) afirmam que, ao contrário de outros métodos, para utilização do balanço de energia não são necessárias informações sobre velocidade do vento nem das propriedades aerodinâmicas da superfície vegetada. Concluíram, ainda, que o método não é afetado pelo barlavento quando a razão de Bowen é pequena, ao invés da relação 1:100 citada na literatura, podendo ser usado com precisão para barlavento vinte vezes a altura da cultura.

Oliver \& Sene (1992) ao calcularem os componentes do balanço de energia através do método das correlações turbulentas, na cultura da videira, var. Airen, na Espanha, em condições de sequeiro, com espaçamento de $2,5 \times 2,5 \mathrm{~m}$, obtiveram, durante o período de 50 dias, da brotação até o completo desenvolvimento foliar, a partição do saldo de radiação em $45 \%$ para o fluxo de sensível, $28 \%$ para o fluxo de calor no solo e $27 \%$ para o fluxo de calor latente. Os elevados valores de fluxos de calor sensível e no solo foram devidos à forte advecção e ao baixo grau de cobertura da superfície pela folhagem (25\%) enquanto o pequeno percentual de Rn para o fluxo de calor latente foi devido à escassez de umidade edáfica. O fluxo de calor sensível, foi duas vezes o fluxo de calor latente.

Heilman et al. (1994) utilizando o razão de Bowen, realizaram o balanço de energia na cultura da videira, variedade Chardonnay, em Lamesa (TX) conduzida no sistema de espaldeira, num espaçamento de 3 x 1,7 m, durante oito dias. $\mathrm{O}$ saldo de radiação variou de 12,5 a $18,9 \mathrm{MJ} \mathrm{m}^{-2} \mathrm{~d}^{-1}$. Sob condições de instabilidade acima das plantas, a partição desse saldo se deu como $17-28 \%$ para fluxo de calor sensível, $11-29 \%$ para fluxo de calor no solo e 46 a $61 \%$ para fluxo de calor latente.

Cunha et al. (1996) verificaram, ao efetuarem o balanço de energia na cultura do milho, no Rio de Janeiro, que o saldo de radiação foi fracionado em $80 \%$ para o fluxo de calor latente, em $14 \%$ para o fluxo de calor sensível e em $6 \%$ para o fluxo de calor no solo. Resultados semelhantes foram encontrados por Teixeira et al. (1997) com a cultura da videira, var. Itália, conduzida no sistema de latada, no Submédio São Francisco. Nesse último estudo, $82 \%$ do saldo de radiação particionados em fluxo de calor latente, $13 \%$ em fluxo de calor sensível e $5 \%$ em fluxo de calor no solo.

Trambouze et al. (1998) utilizando o método do balanço de energia na cultura da videira, concluíram que a vantagem desse método com relação a outros, na estimativa da evapotranspiração, consiste no fato de poder ser usado para período curtos.

O balanço de energia também foi utilizado por Burba et al. (1999) para obtenção dos fluxos de calor latente e sensível de gramíneas (Pharagmites australis) no centro-oeste do Estado de Nebrasca, EUA, em condições úmidas. Na maior parte do desenvolvimento vegetativo o fluxo de calor sensível foi o menor componente do balanço de energia. Durante os estádios iniciais e de pico de crescimento vegetativo, a magnitude média diária foi de $25 \mathrm{~W} \mathrm{~m}^{-2}$, consumindo cerca de 5 a $10 \%$ do saldo de radiação, aumentando em torno de até $50 \mathrm{~W} \mathrm{~m}^{-2}$ no final da senescência. O fluxo de calor latente consumiu cerca de $80-90 \%$ do saldo de radiação, porém durante a senescência esse percentual decresceu para 30-80\%.

O objetivo do presente trabalho foi quantificar a partição da energia solar disponível ao cultivo de bananeira, no primeiro ciclo de produção, irrigada por microaspersão, em diferentes estádios de desenvolvimento e de demanda evaporativa da atmosfera. Pretendeu-se que os resultados sirvam para subsidiar o manejo de água da cultura em condições semelhantes às de cultivo.

\section{MATERIAL E MÉTODOS}

O experimento foi conduzido no Campo Experimental da Embrapa Semi-Árido, no perímetro irrigado de Bebedouro, situado em Petrolina, PE (latitude 9 9'9' S, longitude 40 $22^{\prime} \mathrm{W}$ e altitude $365,5 \mathrm{~m}$ ). O clima da região é do tipo BSwh', segundo a classificação de Köeppen, corresponde a uma região climaticamente árida, cuja quadra chuvosa vai de janeiro a abril.

A cultura estudada foi a bananeira (Musa spp.) cv. Pacovan, durante o primeiro ano de produção, cultivada em solo tipo Latossolo, utilizando-se a técnica da micropropagação, no espaçamento de $3 \times 3 \mathrm{~m}$, irrigada por microaspersão.

Visando assegurar condições de umidade do solo para que a evapotranspiração em nível máximo, o potencial matricial ( $\Psi \mathrm{m})$ de água no solo foi monitorado com tensiômetros de coluna de mercúrio a cada $0,2 \mathrm{~m}$ de profundidade até o nível do sistema radicular, de modo que os valores de $\Psi \mathrm{m}$ fossem sempre superiores a -0,04 MPa. Para tanto, utilizou-se a irrigação ou a precipitação pluvial.

Durante o experimento foram realizadas medições da radiação solar global (RG), do saldo de radiação (Rn), do fluxo de calor no solo $(\mathrm{G})$ e dos gradientes de temperatura do ar e de pressão do vapor, em dois níveis acima da folhagem. Os dados foram coletados através de um sistema automático de aquisição de dados (Micrologger CR10X da Campbell Scientific) o qual foi programado para efetuar aquisições a cada cinco segundos e médias a cada dez minutos. 
A partir das medições do saldo de radiação, do fluxo de calor no solo, dos gradientes de temperatura do ar $(\Delta \mathrm{T})$ e temperatura úmida $(\Delta \mathrm{TU})$ utilizando-se a equação simplificada do balanço de energia (Eq. 1) foram calculados os fluxos de calor latente de evaporação (LE) (Eq. 2) e o fluxo de calor sensível (H) (Eq. 3) empregando-se a razão de Bowen ( $\beta$ ) segundo Webb (1965) (Eq. 4):

$$
\begin{gathered}
\mathrm{Rn}+\mathrm{LE}+\mathrm{G}+\mathrm{H}=0 \\
\mathrm{LE}=-\frac{\mathrm{Rn}+\mathrm{G}}{1+\beta} \\
\mathrm{H}=-(\mathrm{Rn}+\mathrm{LE}+\mathrm{G}) \\
\beta=\left(\frac{\Delta+\gamma}{\gamma} \cdot \frac{\Delta \mathrm{TU}}{\Delta \mathrm{T}}-1\right)
\end{gathered}
$$

em que $\Delta$ é a tangente à curva de saturação do vapor d'água no $\operatorname{ar}\left(\mathrm{mb}^{\circ} \mathrm{C}^{-1}\right)$ em função da temperatura média do termômetro de bulbo úmido, entre os dois níveis onde os psicrômetros foram instalados e $\gamma_{0}$ coeficiente psicrométrico $\left(0,66 \mathrm{mb}{ }^{\circ} \mathrm{C}\right)$.

\section{(A)}

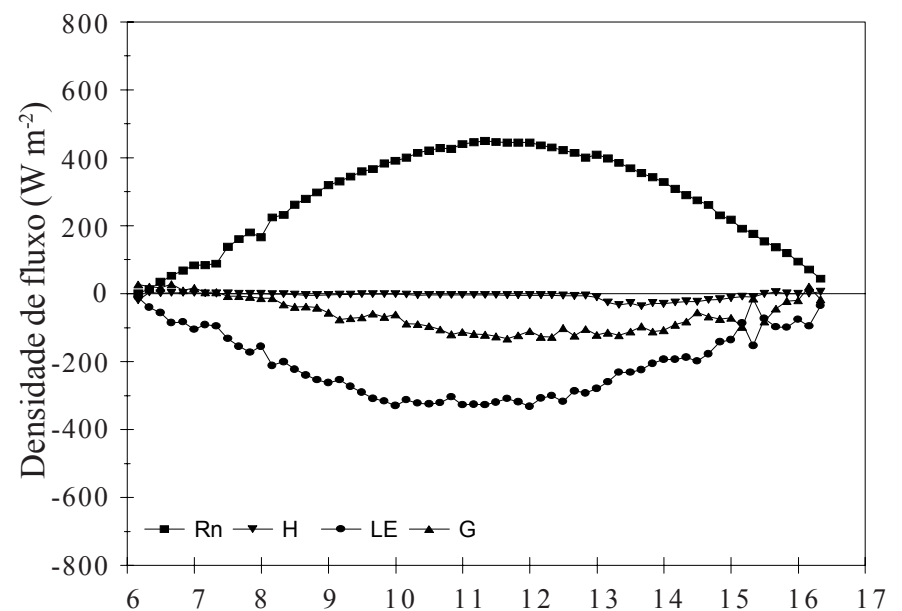

(B)

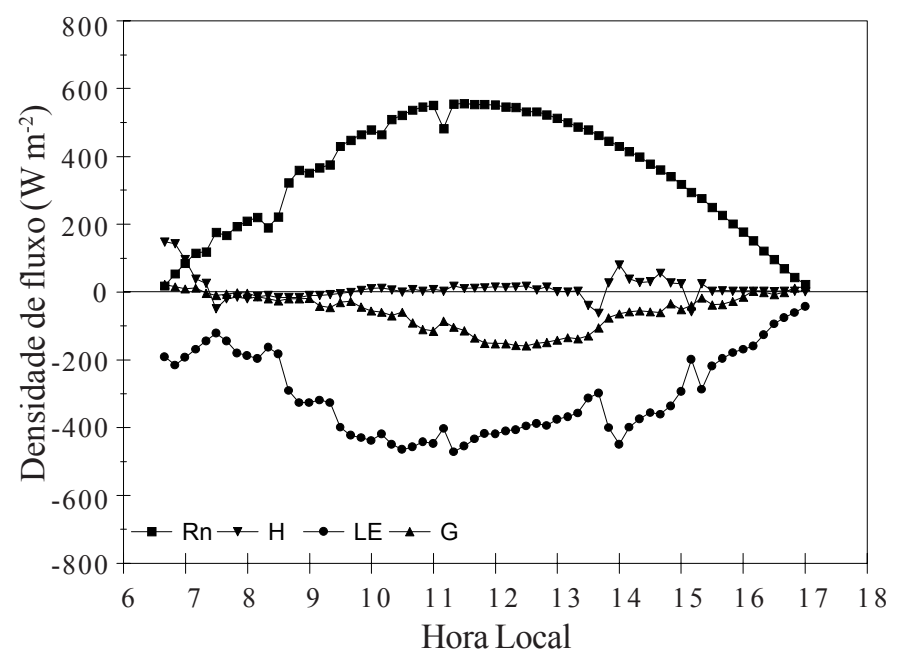

\section{RESULTADOS E DISCUSSÃO}

A variação diurna dos componentes do balanço de energia sobre a cultura da bananeira, em diferentes fases fenológicas, é apresentada na Figura 1, enquanto a Figura 2 mostra as frações da radiação solar $(\mathrm{RG})$ transformada em energia disponível ao sistema (Rn) e a partição dessa energia nos fluxos de calor latente (LE), de calor sensível (H) e de calor no solo (G); já na Figura 3 é apresentado o comportamento estacional dos valores do saldo de radiação e do fluxo de calor latente, levando-se em consideração médias bimestrais no intervalo compreendido entre 120 a 430 dias após o plantio $(D A P)$.

A Figura 1, que apresenta valores diurnos, e a Figura 3, médias bimestrais ao longo do ciclo da cultura, mostram forte influência do saldo de radiação (Rn) sobre o fluxo de calor latente (LE), o que demonstra que, dispondo-se apenas de dados de $\mathrm{Rn}$, já se teria um bom critério para o manejo de irrigação na cultura.

No dia 30/05/99 (Figura 1A), 125 dias após o plantio, o fluxo de calor sensível foi baixo durante o dia, representando apenas $2 \%$ do saldo de radiação, valor semelhante à média durante todo o ciclo. Do total de Rn, $75 \%$ foram utilizados como fluxo de calor latente e $23 \%$ como fluxo de calor no solo. A razão Rn/RG

\section{(C)}

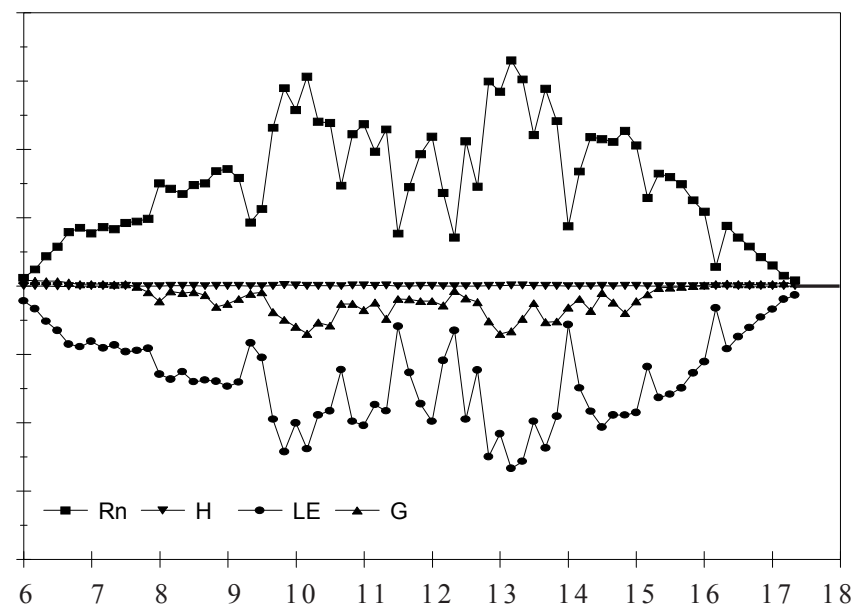

(D)

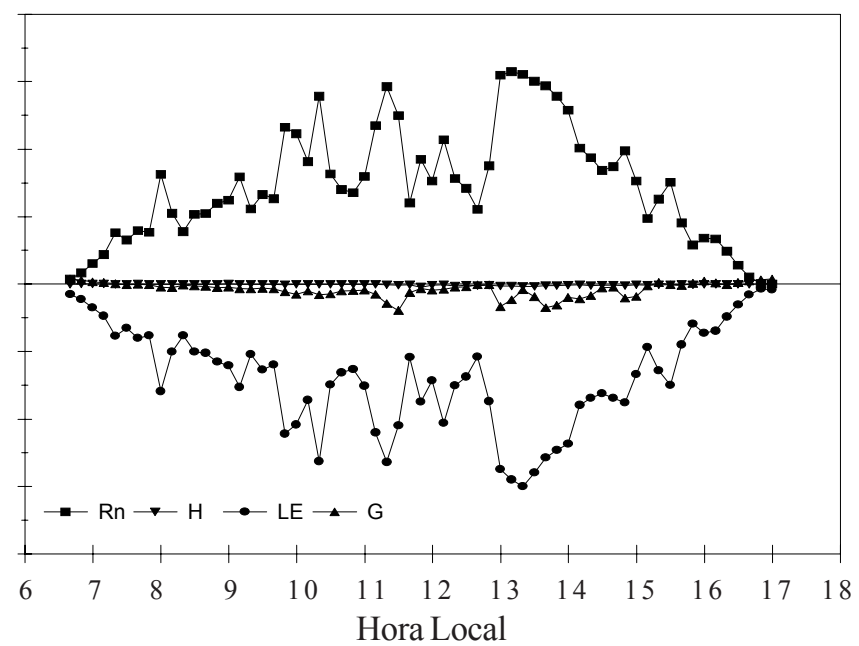

Figura 1. Variação diurna do saldo de radiação (Rn), do fluxo de calor no solo (G), do fluxo de calor latente (LE) e do fluxo de calor sensível (H) nos dias 30/05/99 (A), 28/08/99 (B), 14/12/00 (C) e 08/04/00 (D) 
(A)

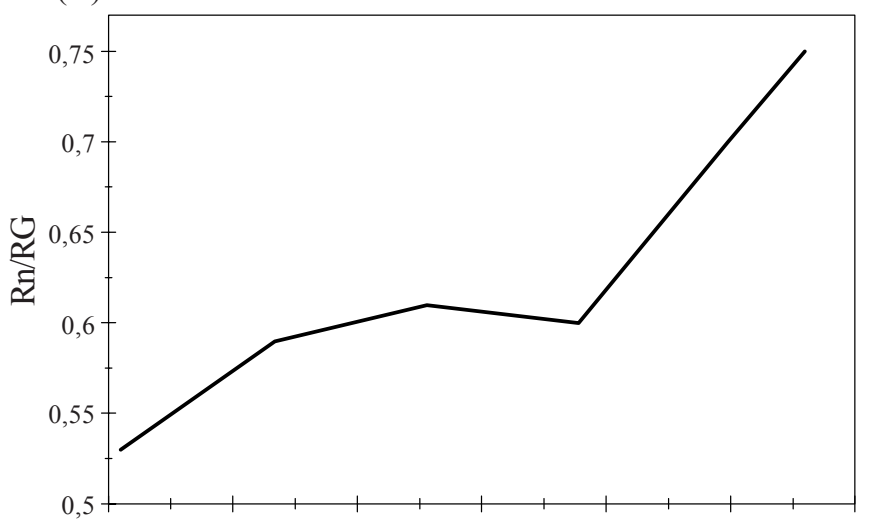

(B)

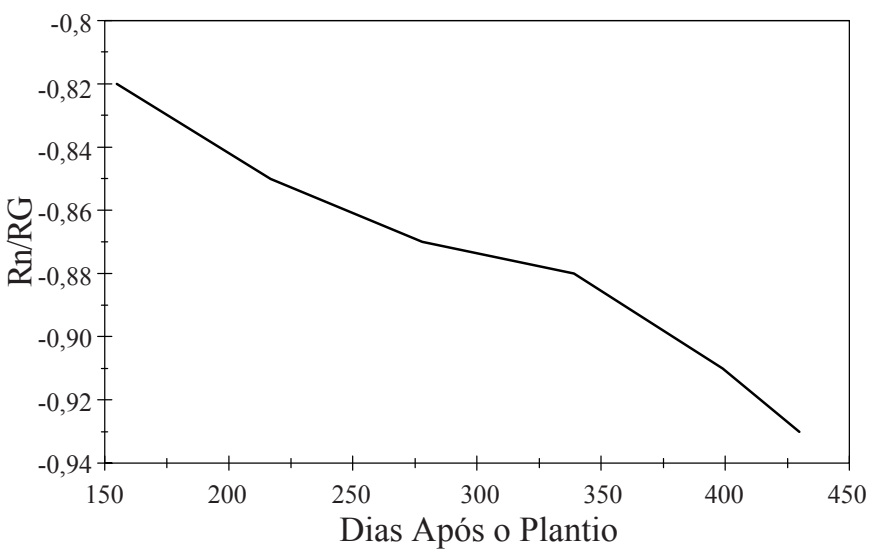

(C)

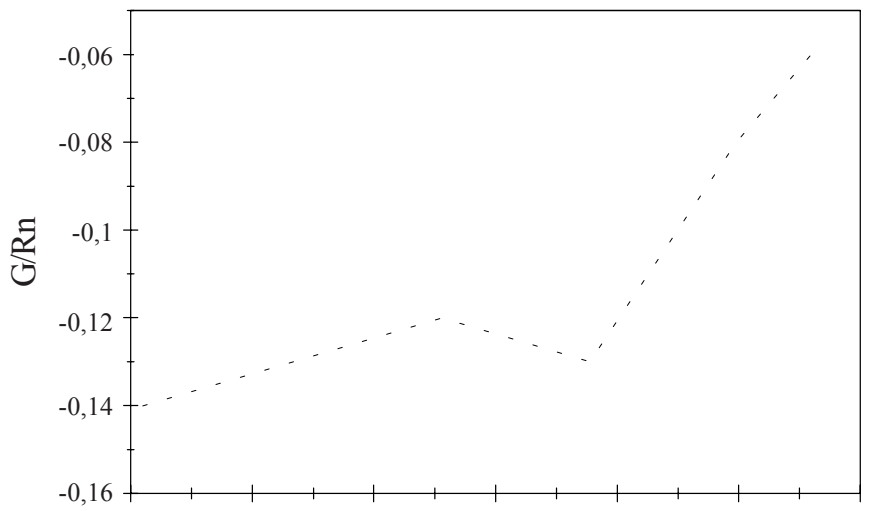

(D)

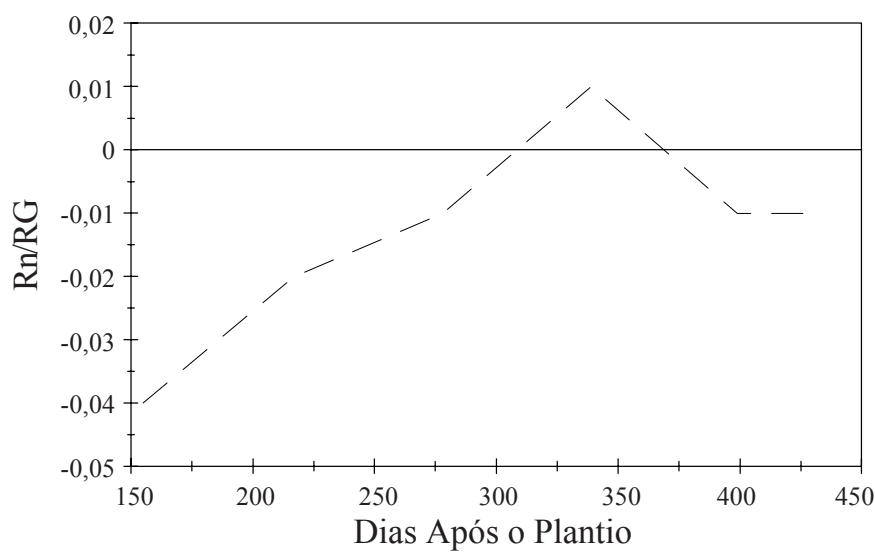

Figura 2. Variações estacionais das relações entre o saldo de radiação (Rn) e a radiação solar global incidente (RG) (A) e dos fluxos de calor latente (LE), de calor no solo $(\mathrm{G})$ de calor sensível $(\mathrm{H})$ para o saldo de radiação $(\mathrm{B}, \mathrm{C}$ e D)

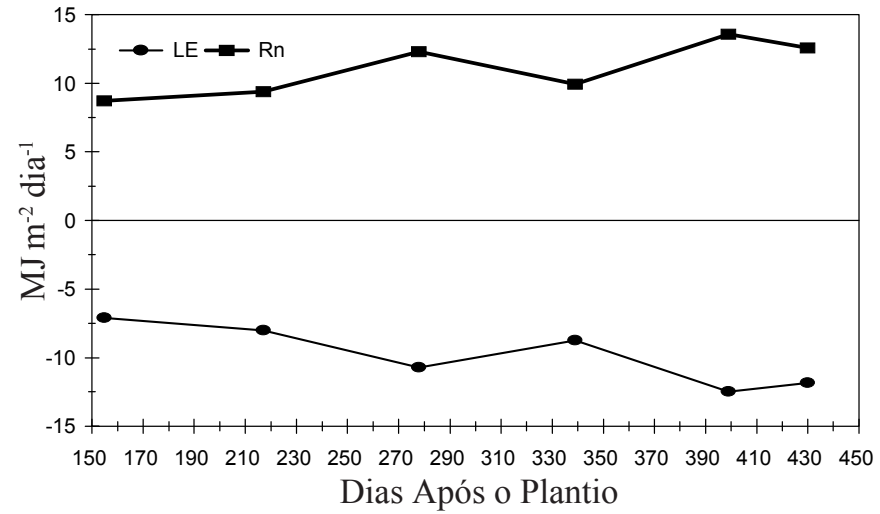

Figura 3. Comportamento estacional do saldo de radiação (Rn) e do fluxo de calor latente (LE) durante o período de maio de 1999 a março de 2000

foi de 0,51 , o menor valor para todo o período de medições. A elevada proporção da energia utilizada como fluxo de calor no solo foi devida à pouca cobertura do solo pela vegetação nesta fase do primeiro ano de produção.

No início do florescimento, cerca de 315 dias após o plantio (Figura 1B) ocorreu aumento da fração do saldo de radiação utilizada no fluxo de calor latente (82\%) enquanto a fração desse saldo, transformada em fluxo de calor sensível, foi a mesma (2\%) e a transformada em fluxo de calor no solo diminuiu para $16 \%$, enquanto a razão $\mathrm{Rn} / \mathrm{RG}$ aumentou para 0,55 .

No final do florescimento, cerca de 422 dias após o plantio (Figura $1 \mathrm{C}$ ) a razão $\mathrm{Rn} / \mathrm{RG}$ subiu para 0,62 e o fluxo de calor latente representou $87 \%$ da energia disponível. A fração do saldo de radiação utilizada como fluxo de calor sensível foi de apenas $1 \%$ e a fração utilizada como fluxo de calor no solo baixou para $12 \%$, devido a um aumento da cobertura do solo pela vegetação.

$\mathrm{Na}$ época de transição da colheita para o início do segundo ano da cultura (Figura 1D) a razão Rn/RG continuou a aumentar para 0,66 , como também a fração do saldo de radiação utilizada como fluxo de calor latente foi de $94 \%$. A porção usada para fluxo de calor sensível continuou muito baixa (1\%) e a utilizada como fluxo de calor no solo alcançou o seu mais baixo valor durante o ciclo $(5 \%)$ devido a maior cobertura do solo.

A Figura 2 apresenta a variação estacional das relações do Rn com RG e com LE, $\mathrm{H} \mathrm{e} \mathrm{G,} \mathrm{entre} 150$ a 450 dias após o plantio (DAP). Na Figura 2A percebe-se o aumento de Rn/RG, de cerca de 0,55 para 0,75 , no final do primeiro ano de produção, com uma média de 0,64 . Com relação à fração do saldo de radiação utilizado como fluxo de calor latente, a Figura 2B mostra aumento de $82 \%$ para $93 \%$ da energia disponível transformada em fluxo de calor latente durante o ciclo, com média de $87 \%$. A Figura $2 \mathrm{C}$ indica que houve diminuição da fração do saldo de radiação utilizado como fluxo de calor no solo, de $14 \%$ para $6 \%$, com média de $11 \%$, enquanto a Figura 2D mostra que houve redução na utilização de Rn, como fluxo de calor sensível de $4 \%$ a $1 \%$, média de $2 \%$, e pequeno fluxo para a cultura na época mais quente do ano.

Esses resultados evidenciaram proporções LE/Rn maiores que outros encontrados para certas fruteiras citados na literatura, o que pode estar relacionado a uma condição de umidade mais 
elevada no solo, associada a uma elevada exigência hídrica da cultura. Deve-se levar em consideração, ainda, a brotação contínua de novos filhotes durante o ciclo da cultura e na transição para o segundo ciclo.

Os pequenos valores de fluxo de calor sensível, semelhantes aos encontrados em locais úmidos (Burba et al., 1999) ocorrem devido ao fato da cultura estar dentro de um perímetro irrigado e, segundo Teixeira (1999) à ocorrência advecção de umidade do Rio São Francisco para a margem esquerda, provocada pelos ventos predominantes de Sudeste, no período de medições.

A Figura 3 mostra a variação dos valores do saldo de radiação e do fluxo de calor latente durante o período de medições. A perfeita simetria da figura sugere que, através da obtenção do saldo de radiação sobre a cultura ou de estimativas desse saldo durante as diferentes fases fenológicas, o produtor já tenha critérios para determinar o consumo hídrico da cultura, para o manejo da irrigação.

A Tabela 1 apresenta os valores médios bimestrais da radiação solar global incidente $(R G)$, do saldo de radiação $(R n)$, do fluxo de calor latente de evaporação (LE), do fluxo de calor sensível $(\mathrm{H})$ e do fluxo de calor no solo $(\mathrm{G})$ na cultura durante o primeiro ano de produção. Observa-se que houve variação no suprimento energético para a cultura, ficando a radiação solar compreendida entre 16,2 a $20,2 \mathrm{MJ} \mathrm{m}^{-2} \mathrm{~d}$, o saldo de radiação entre 8,7 e $13,6 \mathrm{MJ} \mathrm{m}^{-2} \mathrm{~d}$ e o fluxo de calor latente entre 7,12 e 12,5 $\mathrm{MJ} \mathrm{m}^{-2} \mathrm{~d}$, o que evidencia o efeito das condições atmosféricas e da fenologia da cultura sobre o consumo hídrico.

Tabela 1. Comportamento estacional de radiação solar global $(\mathrm{RG})$, saldo de radiação $(\mathrm{Rn})$, fluxo de calor latente de evaporação (LE), fluxo de calor sensível (H) e fluxo de calor no solo $(\mathrm{G})\left(\mathrm{MJ} \mathrm{m}^{-2}\right)$

\begin{tabular}{rcrrrr}
\hline DAP $^{*}$ & RG & \multicolumn{1}{c}{ Rn } & \multicolumn{1}{c}{ LE } & \multicolumn{1}{c}{ H } & \multicolumn{1}{c}{ G } \\
\hline 155 & 16,30 & 8,71 & $-7,12$ & $-0,23$ & $-1,20$ \\
217 & 16,19 & 9,41 & $-7,99$ & $-0,14$ & $-1,20$ \\
278 & 20,19 & 12,32 & $-10,71$ & 0,03 & $-1,48$ \\
339 & 16,54 & 9,96 & $-8,75$ & 0,07 & $-1,28$ \\
399 & 19,34 & 13,58 & $-12,45$ & $-0,06$ & $-1,05$ \\
430 & 16,31 & 12,58 & $-11,85$ & $-0,05$ & $-0,71$ \\
\hline
\end{tabular}

Observação: Os valores negativos indicam fluxos para fora do sistema (Comunidade de plantas) DAP - Dias após o plantio

\section{CONCLUSÕES}

1. O saldo de radiação sobre a cultura da bananeira cv. Pacovan, durante o primeiro ciclo de produção, propagada por micropropagação nas condições climáticas do Vale do São Francisco e na margem esquerda do rio, é utilizado, em média, como $87 \%$ no fluxo de calor latente de evaporação, $11 \%$ no fluxo de calor no solo e $2 \%$ no fluxo de calor sensível.

2. A pequena taxa de fluxo de calor sensível deve ser devido ao fato da cultura estar dentro de um perímetro irrigado e à advecção de umidade do Rio São Francisco, provocada pelos ventos predominantes de Sudeste.

3. A radiação solar global transformada em energia disponível ao sistema e a fração do saldo de radiação convertida em fluxo de calor latente, aumentaram com o ciclo fenológico, enquanto a fração de Rn para aquecer a atmosfera e o solo diminuiu.

4. A relação do saldo de radiação com o fluxo de calor latente sugere que, as medições ou estimativas do saldo de radiação sobre a superfície cultivada, representam um critério eficiente para o manejo de irrigação na cultura.

\section{LITERATURA CITADA}

Angus, D.E.; Watts, P.J. Evapotranspiration: How good is the Bowen ratio method? Agricultural Water Management, Amsterdam, v.8, p.133-150, 1984.

Burba, G.G.; Verma, S.B.; Kim, J. Surface energy fluxes of Phragmites australis in a prairie wetland. Agricultural and Forest Meteorology, Amsterdam, v.94, n.1, p.31-51, 1999.

Cellier, P.; Olioso, A. A simple system for automated long-term Bowen ratio measurement. Agricultural and Forest Meteorology, Amsterdam, v.66, p.81-92, 1993.

Cunha, G.R.; Bergamaschi, H.; Berlato, M.A.A. Balanço de energia em cultura de milho. Revista Brasileira de Agrometeorologia, Santa Maria, v.4, n.1, p.1-14, 1996.

Garrat, J.R. The measurement of evaporation by meteorological methods. Agricultural Water Management, Amsterdam, v.8, p.99-117, 1984.

Gay, L.W. Bowen-ratio measurements at sites C and L. Evapotranspiration measurements of native vegetation, Owens Valley, California. 1986. p.5-18.

Heilman, J.L.; Brittin, C.L. Fetch requirements for Bowen ratio measurements of latent and sensible heat fluxes. Agricultural and Forest Meteorology, Amsterdam, v.4, n.1, p.261-263, 1989.

Heilman, J.L.; McInnes, K.J.; Savage, M.J.; Gesh, R.W.; Lascano, R. J. Soil and canopy energy balance in a west Texas vineyard. Agricultural and Forest Meteorology, Amsterdam, v.71, p.99-114, 1994.

IBGE - Instituto Brasileiro de Geografia e Estatística) Levantamento sistemático da produção agrícola. Rio de Janeiro: IBGE, Anos consultados: 1986 a 1997.

Oliver, H.R.; Sene, K.J. Energy and water balance of developing vines. Agricultural and Forest Meteorology. Amsterdam, v.61, n.2, p.167-185, 1992.

Prueger, J.H.; Hatfield, J.L.; Aase, J.K.; Pikul Jr., J.L. Bowen-ratio comparisons with lysimeter evapotranspiration. Agronomy Journal, Madison, v.89, n.1, p.730-736, 1997.

Steduto, P.; Hsiao, T.C. Maize canopies under two soil water regimes IV. Validity of Bowen ratio-energy balance technique for measuring water vapor and carbon dioxide fluxes at $5 \mathrm{~min}$ intervals. Agricultural and Forest Meteorology, Amsterdam, v.89, n.1, p.215-228, 1998.

Teixeira, A.H de C. Influência do Rio São Francisco no microclima de suas margens. In: Congresso Brasileiro de Agrometeorologia, 11., 1999, Florianópolis, SC, Anais... Florianópolis: Sociedade Brasileira de Agrometeorologia, 1999, p.1605-1610.

Teixeira, A.H. de; Azevedo, P.V. de; Silva, B.B. da; Soares, J.M. Balanço de energia na cultura da videira, cv. "Itália". Revista Brasileira de Agrometeorologia, Santa Maria, v.5, n.2, p.137-141, 1997.

Teixeira, A.H. de; Azevedo, P.V. de; Silva, B.B. da; Soares, J.M. Consumo hídrico e coeficiente de cultura da videira na região de Petrolina, PE. Revista Brasileira de Engenharia Agrícola e Ambiental, Campina Grande, v.3, p.327-330, 1999.

Trambouze, W.; Bertuzzi, P.; Voltz, M. Comparision of methods for estimating actual evapotranspiration in a row-cropped vineyard. Agricultural and Forest Meteorology, Amsterdam, v.91, p. 193-208, 1998.

Webb, E. K. Aerial microclimate. Meteorological Monographs. Boston, v.6, n.28, p.27-58, 1965. 